\title{
Impact of Usage of Social Networking Sites on Youth
}

\author{
Parvathy J. \\ Research Scholar, Dept. Of Computer Sciences \\ Jain University, \\ Bangalore, India
}

\author{
Suchithra R. \\ HoD Department of Computer Sciences, \\ Jain University, \\ Bangalore, India
}

\begin{abstract}
Social Networking Sites (SNS) is a buzz word in today's world due to its enormous growth, customer base and usage. The main focus of this paper is to present an insight into impact of SNS usage on the minds of youth population. SNS has created a fourth world without boundaries. A platform for people to connect and share on $24 / 7 / 365$. It is a common phenomenon across the world where growing citizens (i.e. youth population) are the biggest users and consumers of SNS. This platform has provided the youth a golden opportunity in exchanging knowledge, finding employment and social quotient among them. Increased participation in issues of social importance, providing quick help for the needy are other positive effects of SNS among youth population. On the other side it has created new issues to society to solve. Privacy has taken beating due to overexposure to social media. Participation in chats and discussions in subjects of least importance is killing the valuable creative time among youth. Recent studies has also pointed out that SNS has created change of character, lose in concentration and spike in psychological disorders.
\end{abstract}

\section{General Terms}

Gadgets: Definition for personal communication devices that are hand-held and provide services over internet

Scrapping: A general term used to describe an informal writing communication between people in close relationships.

\section{Keywords}

SNS: Social Networking Sites

SNS Application: Platforms or application that provide Social Networking medium.

\section{INTRODUCTION}

Social Networking Sites (SNS) are independent applications available on Gadgets with active internet connection. WhatsApp, Facebook, Twitter, LinkedIn and other MicroBlogging are major application in this category. Creating a personal profile page is the first step in using SNS. Personal Information, Contact details and preferences are the main information shared here. A personal user name and password is also created by the user for accessing these applications. [1]

SNS is very now very common face of youth and $75 \%$ of them use and figure is growing. SNS promotes self/group marketing, personal growth, sharing of information and knowledge and great opportunities of employment. Other activities include discussion social issues, providing status updates on matters of importance and reaching out to masses for urgent help. [2]

\section{IMPACT OF SOCIAL NETWORKING SITES (SNS) ON YOUTH}

Social Networking sites (SNS) has definitely created high tide in the minds all level of youth population such as working professionals, students and also in the field of research activities. Working professionals are getting new opportunities for job, student are able share knowledge and help their peers in gaining knowledge and people working in the research field are getting more informative database for innovation. The following Table shows the most popular SNS among youth population on various age group.

Table 1: Popular SNS among various youth age groups.

[3]

\begin{tabular}{|c|c|c|c|c|c|c|c|}
\hline \multirow{2}{*}{$\begin{array}{l}\text { Name of Social } \\
\text { Networking } \\
\text { sites }\end{array}$} & Teenagers & $\begin{array}{l}\text { Young } \\
\text { adults }\end{array}$ & Adults & $\begin{array}{c}\text { Working } \\
\text { adults }\end{array}$ & \multicolumn{2}{|c|}{ Frequency } & \multirow[t]{2}{*}{$\begin{array}{l}\text { Cumulative } \\
\text { Percentage }\end{array}$} \\
\hline & $(12-17)$ & $(18-21)$ & $(22+)$ & $(22+)$ & & & \\
\hline Facebook & 49 & 44 & 30 & 21 & 144 & 36 & 36 \\
\hline Whatsapp & 22 & 42 & 45 & 51 & 160 & 40 & 76 \\
\hline Twitter & 12 & 3 & 8 & 6 & 29 & 7.25 & 83.25 \\
\hline Orkut & 0 & 0 & 0 & 3 & 3 & 0.75 & 84 \\
\hline Linkedin & 3 & 5 & 3 & 4 & 15 & 3.75 & 87.75 \\
\hline Youtube & 9 & 3 & 8 & 5 & 25 & 6.25 & 94 \\
\hline Flikr & 5 & 3 & 4 & 9 & 21 & 5.25 & 99.25 \\
\hline Myspace & 0 & 0 & 2 & 1 & 3 & 0.75 & 100 \\
\hline Total & 100 & 100 & 100 & 100 & 400 & $100 \%$ & \\
\hline
\end{tabular}

\subsection{Purpose of SNS usage among youth}

The main purpose of using SNS is to be always in touch. Youth specifically interested in sharing their various experiences. Developing contacts is another activity which young people very much interested and also find establish friendship with people which they met once or twice. Other activities include Sharing content (pictures and motion pictures), and establishing informal way of learning. [4]

The following figure shows the purpose of usage:

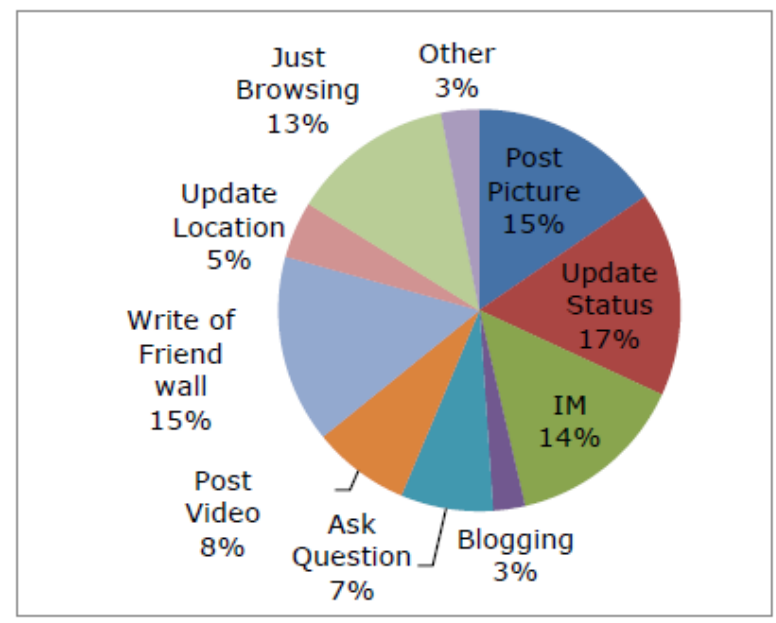

Fig 1: Purpose of usage SNS among youth [5] 


\subsection{Positive Impacts}

Youth representation in social issues is one the main advantages of using SNS. Some of the examples are issues relating to security of women and anti-corruption movement happened across India in which youth has been deciding factor in popularizing and advertising their views. [2]

SNS is an ideal platform to build social relationships through networking and connections with no boundaries are drawn among them. SNS is used as communication media to share personal experiences, pictures, videos. It has also served a common platform to share view on some of social incidents happened across the universe. Adding to the above points they were able connect with their friends and dear-near ones without having to spend too much money and time investment. [6]

One of the advantages of social networking is that able to find our old friends and getting connected with them in far- away place. [6]

SNS has helped the youth population in various aspects. It has helped the young student aspirants in connecting with instructors, researches and eminent subject matter experts in respective field to gain and share knowledge among themselves. Professional interests guided the youth take SNS to enhance their knowledge in their field and able share the knowledge whenever required. [6]

SNS usage among youth accelerated the services to network with professionals for internships and finding employment. Many schools, Universities has implemented SNS alumni's to help the pass outs in find suitable employment and use their knowledge in helping R\&D firms. [6]

\subsection{Negative Impacts}

As discussed before profile creation is one main activity in SNS usage and this activity will share à certain amount personal data. Identity theft is one side effect of sharing personal data and hackers will be easily able to access your personal data and use it for unlawful activities. [7]

Over-usage of SNS has created severe health risk to due to lack of physical activities. As discussed on an average a person spends average about 9 to 10 hours (40\% of time) on using SNS. Due to this young population is at risk of getting cancer, strokes, heart attacks and sleep disorders. On the other side the cases of mental psychiatric also increased because of social isolation. [7]

Due to addiction of SNS; university students are getting effected in their mental and knowledge concentration. Constant usage of SNS has resulted in lower grades for students in university and competitive exams. Also youth being considered as future productive citizens; they are wasting time unnecessary chit-chats and commenting on nonproductive things like posts and pictures. [7].

Studies have established that student population is reducing natural learning capabilities due over dependence on internet. Also natural communication skill is taking hit because of lack of real human contact. The excessive use of net also taking toll health as do not involve in any physical exercise. [8]
Electronic aggression is other negative impact of SNS. More youth is falling into victim of identity theft, rumor spreading, and embracement using emails and psychiatrists are getting more cases of depression cases due to this. [8]

\section{CONCLUSION}

In this paper we have made detailed analysis of what activities the youth population involved with social networking sites. We have also made detailed study of its positive effects and its help to society and its effectiveness in sharing knowledge, information and how it helping university student in helping their studies and research work. We have also see how it improving the creativity of an individual. On the other side we have also seen how SNS it being misused to defame an individual through various bullying methods. Also the article brings out the lack of concentration in normal activities on youth and points out change in behavioral attitude of them.

To sum up every technology has its positives and negatives and people who are using has to extra cautious in using them and requested only use them for good cause.

\section{ACKNOWLEDGEMENTS}

Our sincere thanks to Almighty and eminent personas and electronic medium for preparing this papers. Also would like express gratitude towards our family members for proving unrelenting support to us.

\section{REFERENCES}

[1] Social Networking Service: Wikipedia Knowledge Base.

[2] Pratyasha Jain. 2013 Impact of Social Networking Sites (SNS) on the Youth of India, Research Report.

[3] Ms. Shabnam S. Mahat \& Dr. S. D. Mundhe 2014 Impact of Social Networking Sites (SNS) On The Youth, Sinhgad Institute of Management and Computer Application (SIMCA).

[4] Youth Work and Social Networking 2008 Tim Davies and Pete Cranston

[5] Effects of Social Networking on Adolescent Education 2012 Muhammed Miah, Adnan Omar \& Monique Allison-Golding.

[6] The Effect of Social Network Sites on Adolescents Social and Academic Development: Current Theories and Controversies 2001 June Ahn University of Maryland, College Park, College of Information Studies $\&$ College of Education, USA.

[7] Social Networking Sites - A Critical Analysis of Its Impact on Personal and Social Life, International Journal of Business and Social Science, 2011, Dr. Biswajit Das \& Jyoti Shankar Sahoo KIIT University.

[8] Positive and Negative Effects of Social Networking Sites 2012 News article published in One India Site. Public awareness program. 